\title{
O LUGAR DO BRINQUEDO E DO BRINCAR NA EDUCAÇÃO BÁSICA: UMA PROPOSTA DE PÉ NO CHÃO
}

\author{
EL LUGAR DE LO JUGUETE Y DE LO JUEGO EN LA EDUCACIÓN BÁSICA: UNA \\ PROPUESTA DE PIE LO SUELO
}

\section{THE PLACE OF TOY AND PLAY IN BASIC EDUCATION: A PROPOSAL TO STAND ON THE GROUND}

\author{
Cleomar Ferreira GOMES ${ }^{1}$
}

RESUMO: Este texto apresenta uma oficina com brinquedos, jogos e brincadeiras, endereçadas a professores no cotidiano da Educação Básica. Serviu de instrumento uma aplicação de atividades com professores do ensino fundamental, em estágios de formação, numa escola da periferia de Londrina/PR. Os dados foram coletados quando, envolvendo alunos e seus professores, puderam constatar aquilo que seria de proveito no trato de brinquedos, brincadeiras e jogos com esses participantes. Huizinga, Caillois, Château, Bateson, Sutton-Smith e Brougère serviram de arrimo teórico para lidar com essas informações. Consideramos apropriado relevar pela pena da ciência do jogo e suas disposições didáticas aquilo que pode promover um ambiente lúdico. Com o trabalho feito conseguimos obter algum resultado positivo na educação de crianças, com o uso de brinquedos e brincadeiras, no curso das demandas de aprendizagem. Foi muito rico para pesquisadores e professores saber como lidar com esses conceitos na faina do trabalho cotidiano e como aproveitar esses conhecimentos adquiridos nos cursos de formações específicas e estudos para, na intervenção, auferir algum resultado prático, usando jogos e brincadeiras no solo da formação de crianças e jovens. Lato sensu, os resultados revelaram que os discursos e as práticas são favoráveis à entrada de brinquedos, jogos e brincadeiras no espaço escolar quando são importantes no desenvolvimento natural das crianças. Stricto sensu foi possível analisar as narrativas pelas percepções e noções que adquirem com o uso desses jogos e quando suas intervenções pedagógicas estimulam os espaços de escolarização.

PALAVRAS-CHAVE: Brinquedo. Brincadeira. Cultura lúdica.

RESUMEN: Este texto presenta un taller con juguetes, juegos y travesuras, dirigidos a los maestros en la vida cotidiana de la educación básica. Sirvió como un instrumento de una aplicación de actividades con los maestros de la educación elemental, en las etapas de formación en una escuela en las afueras de Londrina/PR. Los datos se recopilaron cuando involucraban a los estudiantes y sus maestros podían ver, lo que sería jugar juegos con estos participantes. Huizinga, Caillois, Château, Bateson Sutton-Smith y Brougère sirvieron como un sostén teórico para hacer frente a esta información. Consideramos oportuno resaltar la penalización de la ciencia del juego y sus disposiciones didácticas, cuando promueve un ambiente lúdico. Con el trabajo realizado logramos obtener algunos resultados positivos en

${ }^{1}$ Universidade Federal de Mato Grosso (UFMT), Cuiabá - MT - Brasil. Professor Titular. Programa de PósGraduação em Educação. Doutor em Educação. ORCID: https://orcid.org/0000-0003-0451-1011. E-mail: gomescleo.cg@gmail.com 
la educación de los niños, con el uso de juguetes y juegos, en el transcurso de las demandas de aprendizaje. Fue muy rico para que los investigadores y profesores sepan cómo lidiar con estos conceptos en la Faina del trabajo diario y cómo aprovechar este conocimiento adquirido en los cursos de formaciones y estudios específicos para, en la intervención, obtener algún resultado Práctico, utilizando juegos y jugando en el suelo de la formación de niños y jóvenes. Lato sensu, los resultados revelaron que los discursos y prácticas son favorables a la entrada de juguetes, juegos y bromas en el espacio escolar cuando son importantes en el curso natural del desarrollo de los niños. Stricto sensu fue posible analizar las narrativas por las percepciones y nociones que adquieren con el uso de estos juegos y cuando sus intervenciones pedagógicas estimulan los espacios de escolarización.

PALABRAS CLAVE: Juguete. Juego. Cultura lúdica.

ABSTRACT: This paper presents a workshop with toys, games and pranks, addressed to teachers in the daily life of basic education. It served as an instrument an application of activities with teachers of elementary education, in training stages in a school on the outskirts of Londrina/PR. The data were collected when involving students and their teachers could see, what would be playing games with these participants. Huizinga, Caillois, Château, Bateson, Sutton-Smith and Brougère served as a theoretical breadwinner to deal with this information. We consider it appropriate to highlight the penalty of game science and its didactic provisions, which can be promoted in a playful environment. With the work done we managed to obtain some positive results in the education of children, with the use of toys and pranks, in the course of the learning demands. It was very rich for researchers and teachers to know how to deal with these concepts in the fight of daily work and how to take advantage of this knowledge acquired in the courses of specific formations and studies to, in the intervention, to earn some result practical, using games and playing in the soil of the formation of children and young people. Lato sensu, the results revealed that the discourses and practices are favorable to the entry of toys, games and pranks in the school space, when they are important in the natural development of children. Stricto sensu was possible to analyze the narratives by the perceptions and notions they acquire with the use of these games and when their pedagogical interventions stimulate the spaces of schooling.

KEYWORDS: Toy. Pranks. Playful culture.

\section{Introdução}

O pesquisador brasileiro Nélson Rosamilha (1979), ao se indagar sobre as brincadeiras de crianças e a sua angústia pessoal por que as crianças gostam de brincar?, encontra respostas que indicam, nas falas de psicólogos, antropólogos e etólogos, proposições que se distanciam (antagônicas), mas também que se aproximam quando uma hibridação se revela nas condutas lúdicas de seus brincadores. As crianças brincam porque têm excesso de energia; porque ajuda a preparar-se para a vida futura; porque a hereditariedade e o instinto as levam a recapitular as atividades ancestrais e quando brincam descarregam suas emoções de forma 
catártica. Se bem reparadas, todas essas proposições abrem-se para investigações em campos que se avizinham com seus métodos acerca do fenômeno brincar.

O antropólogo e etólogo Gregory Bateson (1977) considera a brincadeira como uma mutação da realidade, porque as crianças que a ela se dedicam trocam sinais que veiculam a mensagem: "isto é uma brincadeira". As crianças, segundo Bateson, sabem separar brincadeira (ficção) de realidade. Brincam de lutar, no lugar de lutar de verdade.

Walter Benjamin (1984), o filósofo frankfurtiano, reconhece que o brincar de crianças significa um libertar-se dos "horrores" do mundo que encontra através da reprodução miniaturizada. Segundo esse autor, as crianças, "rodeadas por um mundo de gigantes", criam para si, enquanto brincam, um pequeno mundo próprio, protegido por leis de sua própria cultura, aquilo que Gilles Brougère (1998) prefere chamar de "cultura lúdica". Brougère \& Dauphagne (2017) reconhece que as crianças dão conta de separar do mundo que encontra, juntando numa só vez, seus espaços, seus objetos e sua legislação, que garante o exercer dessa cultura, e num texto recente "A criança e seus bens" pontua como isso é possível.

Um outro educador e pesquisador francês, Jean Château (1987), quando discorre sobre a brincadeira e jogos de crianças, enxerga que estes significam para elas aquilo que o trabalho representa para o adulto. Como o adulto se sente forte ao realizar as suas obras, a criança sente-se crescer com suas proezas lúdicas. Há uma ideia que persegue a obra de Château marcada mais pelo privilégio do que pelo direito. $\mathrm{O}$ mesmo que dizer, que não há necessidade da pergunta, porque a criança não viveria se não pudesse brincar. Assim, mais que uma conduta cultural, o brincar para ele começa pelas inclinações biológicas dos indivíduos filhotes. O psicólogo alemão Karl Groos (1895) fertiliza uma ideia similar quando estudou essa conduta nos jogos dos animais, no final do século 19, com sua obra "The Play of Animals".

O etólogo austríaco Konrad Lorenz (1986) vê na brincadeira um fenômeno da corporeidade humana. Segundo ele, a rubrica do Homo sapiens é, antes de tudo, uma assinatura do Homo ludens. É muito fácil de entender essa ilação quando as crianças, mesmo antes de ingressar nalguma escola para aquisição de conhecimentos de foro cognitivo, gastam a maior parte do tempo envolvidas com brincadeiras e jogos produzidos no interior de sua cultura de pertença, sem o equívoco de dizer que a "sociedade das crianças" é uma sociedade lúdica.

Silvino Santin (1994), reconhecido filósofo gaúcho da educação física, enxerga que o brincar se encerra num processo criativo, vinculado ao fenômeno da curiosidade quando essa 
valoração do brinquedo ultrapassa o estado biológico, instalando a criatividade — a introdução do totalmente novo.

O psicólogo Alexander Lowen (1984) vê no brinquedo um artefato capaz de produzir manifestações corporais prazerosas, escondido no fenômeno da excitação. O aumento traz prazer e a diminuição traz depressão e tédio. O brinquedo estimula a criança a pular de alegria quando está excitada, a sentir vontade de correr, cantar, dançar, movimentos presentes no ato de brincar.

\section{Algumas características da brincadeira e do jogo segundo determinados teóricos}

O historiador holandês Johan Huizinga (1990) considera a brincadeira/jogo como uma atividade livre, voluntária. Se sujeita a ordens deixa de ser brincadeira. Não é vida corrente nem vida real, porque está sempre a serviço de uma situação ficcional. É uma evasão da vida corrente para uma esfera temporária duma vida imaginada. Distingue-se da vida comum em tempo e espaço, porque tem caminho e sentido próprios, embora suas ações possam ter inspiração nos princípios de realidade. Fixa-se como fenômeno cultural e pode ser repetido a qualquer momento. Isso se revela quando um adulto se surpreende ao ver crianças brincando, se recorda nas reminiscências possíveis, algo tão parecido, senão igual ao que fazia quando criança. Cria ordem e é ordem: introduz na confusão da vida e na imperfeição do mundo uma perfeição temporária e limitada. A liberdade ou o autotelismo, como diria Piaget (1978), não elimina a presença de legislação criada ou recebida para organizar as atividades em curso. Cria uma sensação de estar "separadamente juntos", porque partilha algo importante, do qual não se pode separar.

Para o britânico James Christie apud Kishimoto (1997), quando a criança brinca, a realidade interna predomina sobre a externa. Um bicho de pelúcia faz a vez de filhinho. Quando brinca livremente e se satisfaz, isso resulta em aspectos positivos corporais, morais e sociais para ela. Propicia a ensaios de novas combinações de ideias e de comportamentos do que em outras atividades não-recreativas. Sua atenção se concentra na atividade em si e não em seus resultados. $\mathrm{O}$ jogo utilizado em sala de aula dá prioridade à aprendizagem de noções e habilidades.

O sociólogo francês Roger Caillois (2018) repete a exposição de Huizinga quanto à liberdade exposta no rito do ato de jogar. Para esse autor, se um brincador ou um jogador fosse obrigado a brincar/jogar, o jogo perderia sua "natureza de diversão atraente e alegre". Perderia a sua primazia em entreter, distrair e divertir os envolvidos. É delimitada: é dada e 
acontecida dentro de certo espaço e certo tempo. É incerta, porque não se prevê nem seu desenrolar nem seu resultado, além de deixar o jogador inventar. É improdutiva porque não produz nem bens, nem riquezas - exceto alteração de propriedade dentro do círculo dos jogadores. É regulamentada quando se sujeita a convenções criadas pelo jogador/brincador. É fictícia pois há uma realidade outra ou uma irrealidade em relação à vida normal, uma força extrínseca para organizar o cenário.

\section{Brinquedos e brincadeiras segundo cinco teóricos da atualidade}

No livro "A História do Brinquedo e dos Jogos: Brincar através dos tempos", do historiador e pedagogo Michel Manson (2002), a educação familiar se beneficia pela crescente produção dos livros infantis, quando os brinquedos ocupam um lugar considerável. Com a evolução do sistema educativo — os brinquedos são incluídos nesse cenário com horas recreativas - há um momento para o brinquedo. Segue o autor dizendo que o brinquedo se tornava um utensílio pedagógico, por perceberem no artefato as "artimanhas pedagógicas".

Segundo alguns teóricos da atualidade, como Gilles Brougère (2001), o brinquedo é um objeto destinado à criança, e falar em brinquedo para um adulto tornar-se, sempre, um motivo de zombaria, de ligação com a infância.

Brinquedo, na França, é objeto de criança, os adultos os guardam escondidos como relíquias, por preconceito de se passarem por infantil, relata a professora francesa (Barthelemy-Ruiz, 2001). O Brinquedo, continua Manson (2001), é um objeto destinado à criança, para os adultos só se for em sentido metafórico. Para o pesquisador havaino Jay Tobin apud Gomes (2001), todos os adultos têm brinquedos, só que nós os chamamos de hobby.

Para a pedagoga uspiana Tizuko Kishimoto (2001), o brinquedo para o adulto é uma forma que ele utiliza para fugir da realidade, ao contrário da criança que usa a realidade para entrar no imaginário. Não é incomum encontrar uma criança numa cena lúdica representando com seus brinquedos (casinhas para as meninas, carrinhos para os meninos) uma situação do mundo adulto.

\section{Do método}

Seguindo a trilha dalguns metodologistas, lançamos mão do método, porque ele nos fornece um conjunto de atividades sistemáticas e racionais que nos dá a segurança e a 
economia necessárias, que nos permitem alcançar o objetivo, isto é, os conhecimentos válidos e acertados, obtidos no caminho a ser seguido, já eliminando os erros e auxiliando nas decisões das tarefas do cientista.

Cervo e Bervian (2002, p. 23-25) consideram que não criamos um método, porque ele está intrinsecamente ligado ao assunto da pesquisa. Isso é dito no exato instante quando a investigação brota do problema de eleição, por isso o uso desse conjunto de etapas de que se serve o método científico, para fornecer apoio necessário na busca de um resultado para as questões norteadoras da pesquisa que irá estimular o nascimento desse caminho; que ajudará o pesquisador a realizar tal investigação; a desvelar seus mistérios e a produzir suas constatações, inspiradas pelas suposições de trabalho. É um jeito de pensar que o caminho o méthodos ${ }^{2}$ - vá se fazendo na teia de tarefas a que se entrega o cientista.

Foi se pautando por estas assertivas que entramos em campo, com - um método ou critérios para a busca da explicação das questões ou dos problemas específicos, descritos no que seriam as brincadeiras vistas e feitas pelas professoras de crianças na educação básica e da educação física em particular.

Para preservar a identidade dos participantes, acatei a ideia de usar as três primeiras letras de seu nome, entre pontos: (MARIA = M.A.R./F), anexando com barra o sexo, como se fossem iniciais. Assim, supomos que a privacidade do/a entrevistado/a e pesquisado/a teria uma maior segurança, o que foi uma opção acertada.

Supondo que o brincar é uma atitude com propósitos lúdico-recreativos, exercida por homens e animais filhotes, que envolve o ser brincante, que o brinquedo seria todo o material ou as "coisas" que se utilizam como objeto para brincar e que a brincadeira seria essa atividade simulada por nossa imaginação, "entramos em campo" com o objetivo cardeal de investigar a cultura do brinquedo e da brincadeira pela percepção das professoras da escola “Garcia Villar”.

Para tanto, aplicamos um roteiro semiestruturado de questões às crianças e aos professores quando identificamos a noção que as professoras têm de brincadeira e o modo como desenvolvem esta atividade no ambiente escolar. De modo particular foi possível analisar as formas de envolvimento e intervenções destas profissionais no momento da brincadeira das crianças.

Todas as atividades que vimos em sala, na quadra e no pátio nos sugeriram que tanto os professores de sala, quanto os professores de ed. física, sabem dos "benefícios" que as

2 Méthodos, ou "pesquisa, busca, p.ext. estudo metódico de um tema", de metá, que quer dizer "atrás", em seguida, através, e hodós, que quer dizer caminho. 
brincadeiras podem, se bem conduzidas, promover aos alunos em seu estágio de aprendizagem. Há relatos de professoras que não sabem dar aula sem lançar mão das atividades lúdicas, como veremos nos seus depoimentos, a seguir.

\section{Resultados: diferenças entre brinquedo e brincadeira segundo a criança}

Num primeiro momento veremos pelas vozes das crianças no que se refere à compreensão, uso e utilidades dos brinquedos e das brincadeiras, tanto na escola quanto em sua vida cotidiana. Criamos cinco categorias de perguntas, separadas por aquilo que eles julgam ser de maior importância.

a) associam brinquedo a um objeto, a uma "coisa":

É que brinquedo... tem que usar brinquedo. E brincadeira pode brincar sem coisas. O brinquedo usa coisas e a brincadeira é sem coisas... (A.R.M./F - 7 anos $-1^{a}$ S.).

Brinquedo você pega as coisas e brinca. E brincadeira você não brinca com as coisas... (K.A.C./F -10 anos $-4^{\text {a }} \mathrm{S}$.).

Na brincadeira, você não precisa dessas coisas pra você ficar brincando. Você pode brincar com quem você quiser, que você não precisa dessas coisas eletrônicas... (L.E.S./M - 7 anos $-1^{\text {a }}$ S.).

b) a ideia de perda ou "estrago":

De carrinho é que às vezes estraga. Às vezes tem uns pior, assim, que estraga também. E de Pega-pega tem que correr, assim, pra não pegar... e não estraga a brincadeira... (N.I.T./M -6 anos $-1^{\text {a }}$ S.).

É que brinquedo a gente brinca e pode estragar. Agora brincadeira, não. A gente pode brincar até quando a gente quiser... A gente pode trepar em árvore. Brinquedo, não. Brinquedo se a gente joga no chão assim, se é caro, já estraga na hora... (L.U.A./M - 9 anos - $3^{\text {a }}$ S.).

c) a coisas que não foram criadas por eles, mas para eles:

A brincadeira, a gente que inventa, né? Com o brinquedo, cada brinquedo já tem o tipo de brincar... mas se as pessoas quiser inventar um tipo, também dá... mas geralmente o brinquedo já vem com o jeito inventado. E a brincadeira, não, a gente inventa, mesmo. (A.M.G./F - 9 anos - $3^{\mathrm{a}} \mathrm{S}$.).

Ah! Eu acho muita... A brincadeira é feita assim... a brincadeira você inventa, você faz a brincadeira, o brinquedo não! Eles fazem, eles inventam e a gente compra. (P.E.A./M - 11 anos $-4^{\mathrm{a}}$ S.). 
d) a diferença mais flagrante tem a ver com o corporal, com o movimento:

É que um pula, o outro a gente fica sentado... Na brincadeira, a gente corre mais e na Casinha a gente fica mais sentado, assim... (A.N.C./F - 9 anos $3^{\mathrm{a}} \mathrm{S}$.).

Muita diferença! Brinquedo, você brinca mais sentado. Agora uma brincadeira, você já corre. Sua! (L.U.S/M -8 anos $-2^{\mathrm{a}}$ S.).

Você fica... por exemplo eu gosto de brincar de Barbie. Aí, eu fico lá parada, eu finjo que a Barbie tá andando, não sei o quê, mas eu fico no lugar. Agora se eu vou brincar lá na rua, daquelas brincadeiras, eu vou correr, eu vou pular, eu posso até cair no chão... (B.E.P./F - 10 anos $-4^{\mathrm{a}}$ S.).

e) como alguns teóricos, há aquelas que não enxergam diferenças:

Ah! Brincadeira e brinquedo é a mesma coisa! É porque brinquedo brinca... brincadeira também. A gente brinca brincadeira com brinquedo... (D.A.H./F -10 anos $-2^{\mathrm{a}} \mathrm{S}$.).

Eu acho que não tem diferença porque dos dois, só muda o nome, porque com os dois você brinca... só é que um chama brinquedo e outro brincadeira. Mas é tudo um brinquedo, porque a gente se diverte... Assim como eu se divirto com meus brinquedos eu se divirto com a brincadeira que a gente inventa... (S.U.D./F -12 anos $-2^{\mathrm{a}}$ S.).

Na sala de aula, pelas vozes dos professores, se preconiza um discurso que corrobora o grau de importância que tem essas brincadeiras e esses jogos no rito das aulas. Se por um lado os alunos enxergam uma necessidade de brincar, por outro, os professores enxergam como uma oportunidade no uso, seja pela plasticidade, leveza ou alacridade que essas atividades promovem. Ninguém discorda que os jogos são um excelente aliado do oficio de ensinar, e divergir sobre essa prerrogativa é descabido e ultrapassado, mesmo que não se tenha garantia de sucesso.

\section{A escola e a brincadeira "institucionalizada".}

Os joguinhos e brincadeiras, na sala, servem sempre de "presas" que têm por trás uma serventia, um objetivo de cor pedagógica:

A) é dirigida ou sugerida pela professora para resolver questões centradas nas dificuldades dos alunos:

Às vezes eu brinco quando, por exemplo, eu tô dando Ortografia. Pra trabalhar os dois "rr": "A mamãe fez um suco. Um suco de laranja, limão... 
Aí depois que ela fez esse suco, ela colocou esse suco onde?" Aí eles falam: "na jarra". Aí eu escrevo no quadro e explico pra eles a posição dos dois 'rr'. É pra eles terem noção dum ' $r$ ' brando pro outro ' $r$ '. (A.L.D./F -46 anos).

A gente brinca de "O que é o que é?" uma brincadeira que gosto de fazer com eles porque trabalha sobre animais. Por exemplo, eu escrevo no quadro um animal com 5 patas, que é herbívoro... pra eles matar a Charada. (R.O.S./F -51 anos).

Quando eu faço a brincadeira dirigida, aí eu tenho alguns objetivos práticos, nisso. Por exemplo, um Quebra-cabeça é pra mim dar a noção de espaço, de tempo, de ordenação, de sequência e vai por aí a fora... (S.I.L./F -29 anos)

A brincadeira é necessária na aprendizagem. Se não tiver brincadeira, não aprende... A Alfabetização não acontece sem brincar. Eu acho isso. Os meus alunos de $1^{a}$. Série aprendem a contar jogando bola-de-gude... (M.A.B./F 29 anos).

B) no fim da aula como ocupação de um tempo livre para não perturbar os colegas e principalmente a professora:

Aqueles que vão terminando, ao invés deles ficarem conversando alto ou andando pela sala brincam ali no canto... Às vezes tem um gibi. Odoletá. Figurinha. São brincadeiras que não atrapalham. Terminou a atividade, eles vão querer passear pela sala. Então, ao invés de ficar passeando pela sala e ficar atrapalhando os colegas, ficam entre eles, né? (E.L.E./F - 28 anos).

A gente sempre tá fazendo uma brincadeira no final da aula, quando sobra um tempo. Aí eu mesmo brinco também com eles. Geralmente é algum jogo como Morto-vivo que tem de levantar e agachar. E o Careca-cabeludo, então, que é com gesto... (H.E.L./F - 25 anos).

C) como uma trégua no trabalho intelectual, sugerido pelos meninos e entendido pelas professoras como descontração, distração ou "refresco":

Às vezes um meio de descontração. Muitas vezes eles brincam pra extravasar e isso ajuda na integração deles. Eu vejo. Mas eles sugerem brincar de dançar, cantar, Jogo do silêncio... (R.O.A./F - 43 anos).

Por exemplo... você trabalhou Português e Matemática, já estão cansados, né? Então é um momento de distração, um momento de participar em grupo... pra dar um refrescada... (R.S.I./F -28 anos).

Os jogos e as brincadeiras, na quadra, servem de estratégias para aprendizagens em grupos, atividades de estafetas que têm por trás uma aprendizagem do espaço e/ou da habilidade de objetos, mas a cor pedagógica deve estar também presente: 
A) há professores de Educação Física que enxergam na brincadeira do aluno uma demonstração de agressividade ou mau gosto - empurrar, chutar, meter o pé, puxar o cabelo, são os verbos mais citados por eles:

Eu vejo assim... eles têm muita brincadeira de mau gosto... como empurrar, chutar, machucar, de meter o pé um no outro. E isso eu considero uma brincadeira de mau gosto. Daí eu sento todo mundo e faço aquele sermão que daí você dá trela pra aula virar um auê, né? Daí vira bagunça. (P.A.T./F -27 anos).

B) há também aqueles professores que enxergam no gesto do aluno sinais de um excesso de energia que é preciso "controlar":

Se você for reparar dentro da sala de aula, o moleque... não aguenta ficar ali dentro. Ainda mais no calor, né? À hora que você chega na porta eles querem voar em cima de você pra sair de dentro da sala, certo? À hora que chega lá fora, a energia é tanta, o gás que eles têm é tanto, que se você não der uma atividade, assim, pra eles gastarem, você não consegue controlar não, meu! (E.D.G./M - 35 anos).

No pátio, os ajuntamentos são inspirados, muitas vezes, em jogos e brincadeiras que os alunos aprendem nas aulas de educação física ou que trazem de outras experiências lúdicas, com estratégias, mais para se entreter, distrair e divertir do que explicitamente arvorarem por alguma aprendizagem.

A) os meninos no pátio são um bando que se forma para "correr feito uns doidos...".

Eles brincam no pátio, na hora do recreio, que eu vejo. Mas é sempre de correr, jogando o chinelo do outro, na árvore... (Z.U.L./F - 31 anos).

Olha, por mais que eles falem pra não correr, é correndo, empurrando. [...] Eu percebo que brincam muito de empurrar, de bater. (S.I.L./F - 29 anos).

B) também para brigas, pontapés, xingamento, empurra-empurra, enfim, um ajuntamento de endiabrados:

[...] De lutar, de correr, de chutar, de machucar... Olha, tem um menino aqui que jogou uma menina no chão e a menina bateu a cabeça no chão e teve que ser internada. Não faz nem um mês. É esse tipo de brincadeira que se vê! (S.O.N./F -40 anos).

Nossa! bota capeta nisso. E eu já cheguei a falar com a mãe de alguns aqui que tava demais, na hora do intervalo, com brincadeiras muito violentas, sabe? (S.I.L./F -40 anos). 


\section{Considerações finais}

As falas dos adultos quando se refere às brincadeiras das crianças, no pátio ou na quadra, sem a presença da autoridade dalgum adulto, suscita uma visão mais estreita quanto ao comportamento dessas crianças. Sentenças como: "um bando de endiabrados", "um ajuntamento de doidos", "brincadeiras muito violentas", servem de exemplos para aquilo que os professores e gestores enxergam como condutas agressivas.

O trabalho do cientista não tem por tarefa de defender os alunos dalgum gesto agressivo. Não se considera nem "anjos", nem "demônios", mas quando se pergunta a eles é possível ver, pelas observações ratificadas em suas falas, que esses gestos que denotam agressividade não passam de uma simulação, ou próprio daquilo que Bateson (1977) chamou de "metacomunicação", isto é, uma conduta própria da liturgia das brincadeiras e dos jogos. Jogar o chinelo do colega na árvore pode significar um arremesso de disco; uma "avoadeira" (passar a perna por cima da cabeça do colega agachado) é a repetição do gesto da Capoeira; enforcamentos às vezes revelam os gestos de golpes de um Judô ou de um abraço com afeto.

Quanto ao brinquedo, foi possível constatar que esse artefato pode apresentar-se um constructo tecnológico a partir da aquisição econômica que é determinada pela cultura de cada grupo, de cada classe. Desse ponto de vista, assim como os meninos de um condomínio de classe média brincam de videogame, quando seus pais podem comprar, noutra realidade, os meninos de periferias, em situação de escassez tecnológica, brincam de carrinhos feito de sabugo de milho, de garrafas pet, ou daquilo que tiverem à mão.

O pátio, mesmo livre das tarefas da sala e quadra, não é lugar estrito para brincadeiras livres que os meninos e meninas chamam de "normal". A brincadeira do pátio, por mais que reproduza os ritos de uma aula de educação física, por ser semelhante à brincadeira de rua é um perigo. Precisa ser vigiada por uma "tia" especializada em vigiar recreios, ajudada pelos outros tios em outros momentos diferentes de recreio. Os meninos e meninas registram que essa administração de seu tempo e espaço de recreio é uma condição sine qua non.

Quando as crianças aqui consideradas se referiam a suas brincadeiras dentro e fora da escola, falavam de bonecas, carrinhos inventados, bichos construídos, mobília fabricada. Comidinhas, armas poderosas, fazendas enormes, balanços.

As informações dadas pelos alunos desses mesmos professores quanto aos brinquedos e brincadeiras dizem que também brincam fora da escola e que são diferentes em quantidade e qualidade. A faculdade de brincar é garantida pela etologia e pelos materiais que possuem. Numa palavra: os meninos brincam! Brincam com os colegas, dentro, brincam com os 
vizinhos, fora. Brincam de três, de quatro, de muitos, de todos que chegam para brincar. Brincam nas varandas, nos quintais, nos campinhos, praças, ruas... brincam no shopping center. Nas ruas, há uma justificativa que se repete: “Às vezes eu fico na rua brincando... Eu gosto mais de brincar na rua porque lá tem mais espaço, tem mais gente” (L.E.C./M - 9 anos).

A proposta de brincar ao rés do chão se assenta naquilo que as crianças sugerem, quando se é mais "gostoso", mais “à vontade", quando se junta "mais gente” para brincar. Daí que deixo o "campo" com a proposição das próprias crianças, de que brincar é preciso! Nem precisa consultar os especialistas nas suas distintas áreas do conhecimento humano, basta lembrar-se de quem já foi criança um dia, e lá se salta, das reminiscências dalguma sacola, uma Queimada, um Bete, um Rouba-bandeira, uma Balança-caixão, um Pega-pega, um Esconde-esconde... brincadeiras e jogos; um Rolimã, um carrinho feito com resto de latas, uma boneca feita de trapos da avó... artefatos que respondem pelo nome de brinquedos que vão se constituir nos "bens" de crianças que fomos, de meninos e meninas que continuamos a ser.

Seja para as demandas das aprendizagens de foro moral, cultural, social, cognitiva, motora ou simbólica, esses brinquedos, jogos e brincadeiras são e serão uma boa companhia para nos pôr de pé no chão.

\section{REFERÊNCIAS}

BARTHÉLÉMY-RUIZ, Chantal. J Comme jura. In: Le jouet: valeurs et paradoxes d'un petit objet secret. Paris: Éditions Autrement, 1992.

BATESON, Gregory. Une théorie du jeu et du fantasme. In: Vers une écologie de l'esprit. Paris: Le Seuil, 1977.

BENJAMIN, Walter. Reflexões: a criança, o brinquedo, a educação. São Paulo: Summus, 1984.

BROUGÈRE, Gilles; DAUPHRAGNE, Antoine. Les biens de l'enfant. Paris: Nouveau Monde éditions, 2017.

BROUGÈRE, Gilles. A criança e a cultura lúdica. In: O brincar e suas teorias. São Paulo: Pioneira, 1998.

CAILLOIS, Roger. Os jogos e os homens: a máscara e a vertigem. Petrópolis: Vozes, 2017. CHÂTEAU, Jean. O jogo e a criança. São Paulo: Summus, 1987. 
GOMES, Cleomar F. As brincadeiras e os jogos nos anos iniciais do Ensino Fundamental. In: MOREIRA, Evando C. A educação Física na rede municipal de Cuiabá: uma proposta de construção coletiva. 2. ed. Cuiabá: Edufmt, 2016.

GOMES, Cleomar F. Meninos e brincadeiras de interlagos: um estudo etnográfico da ludicidade. 2001. 361 f. Tese (Doutorado em Educação) - Faculdade Educação de São Paulo, FEUSP/USP, São Paulo, 2001.

GROOS, Karl. The play of animals. New York: D. Appleton and Company, 1898.

HUIZINGA. Johan. Homo ludens: o jogo como elemento da cultura. São Paulo: Perspectiva 1990.

KISHIMOTO, Tizuko M. Jogo, brinquedo, brincadeira e a educação. São Paulo: Cortez, 1997.

KISHIMOTO, Tizuko M. O jogo e a educação infantil. São Paulo: Pioneira, 1994.

LORENZ, Konrad. A demolição do homem: crítica à falsa religião do progresso. São Paulo: Brasiliense, 1986.

LOWEN, Alexander. Prazer: uma abordagem criativa da vida. São Paulo: Summus, 1984.

MANSON, Michel. História do brinquedo e dos jogos: brincar através dos tempos. Lisboa: Editoria Teorema, 2002.

PIAGET, Jean. A formação do símbolo na criança: imitação, jogo e sonho, imagem e representação. Rio de Janeiro: Guanabara, 1978.

ROSAMILHA, Nélson. Psicologia do jogo e aprendizagem infantil. São Paulo: Pioneira, 1979.

SANTIN, Silvino. Educação física: da alegria do lúdico à opressão do rendimento. Porto Alegre: Edições EST. 1994.

SUTTON-SMITH, Brian. A ambiguidade da brincadeira. Petrópolis: Vozes, 2017. 


\section{Como referenciar este artigo}

GOMES, Cleomar Ferreira. O lugar do brinquedo e do brincar na educação básica: uma proposta de pé no chão. Revista Ibero-Americana de Estudos em Educação, Araraquara, v. 15 , n. 3, p. 1236-1249, jul./set. 2020. e-ISSN: 1982-5587. DOI: https://doi.org/10.21723/riaee.v15i3.12425

Submetido em: 11/04/2019

Revisões requeridas em: 20/08/2019

Aprovado em: 24/10/2019

Publicado em: 20/02/2020 